\title{
The feasibility of short-segment Schanz screw implanted in an oblique downward direction for the treatment of lumbar 1 burst fracture: a finite element analysis
}

\author{
Jifeng Liư ${ }^{\dagger}$, Sheng Yang ${ }^{* \dagger}$, Fei Zhou ${ }^{\dagger}$, Jianmin Lu, Chunyang Xia, Huanhuan Wang and Chao Chen
}

\begin{abstract}
Background: To evaluate the biomechanical properties of short-segment Schanz screw implanted in an oblique downward direction for the treatment of lumbar 1 burst fracture using a finite element analysis.

Methods: The Universal Spine System (USS) fixation model for adjacent upper and lower vertebrae (T12 and L2) of lumbar 1 vertebra burst fracture was established. During flexion/extension, lateral bending, and rotation, the screw stress and the displacement of bone defect area of the injured vertebrae were evaluated when the downward inserted angle between the long axis of the screws and superior endplate of the adjacent vertebrae was set to $0^{\circ}$ (group A), $5^{\circ}$ (group B), $10^{\circ}$ (group C), and 15\%(group D). There were 6 models in each group.

Results: There were no significant differences in the maximum screw stress among all the groups during flexion/ extension, lateral bending, and rotation $(P>0.05)$. There were no significant differences in the maximum displacement of the bone defect area of the injured vertebrae among all the groups during flexion/extension, lateral bending, and rotation ( $P>0.05)$.

Conclusion: Short-segment Schanz screw implanted in an oblique downward direction with different angles $\left(0^{\circ}\right)$ parellel, $5^{\circ}, 10^{\circ}$, and $15^{\circ}$ ) did not change the maximum stress of the screws, and there was a lower risk of screw breakage in all groups during flexion/extension, lateral bending, and rotation. In addition, the displacement of the injured vertebra defect area had no significant changes with the change of angles.
\end{abstract}

Keywords: Lumbar burst fracture, Schanz screw, Oblique downward direction, Biomechanics

\section{Background}

Burst fractures of the thoracolumbar spine often require surgical treatment; however, there is no uniform standard whether the stenotic spinal canal needs decompression or whether the intraspinal retropulsed bone fragments need to be removed for the fracture combined with nerve injury

\footnotetext{
*Correspondence: yangsheng_88@163.com

†jifeng Liu, Sheng Yang, and Fei Zhou equally contributed to this paper and thus shared the co-first authorship.

Department of Orthopaedics, Affiliated Zhongshan Hospital of Dalian University, 6 Jiefang Street, Zhongshan District, Dalian 116001, Liaoning, China
}

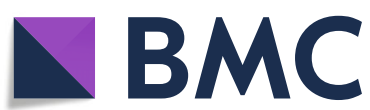

(c) The Author(s). 2020 Open Access This article is licensed under a Creative Commons Attribution 4.0 International License, which permits use, sharing, adaptation, distribution and reproduction in any medium or format, as long as you give appropriate credit to the original author(s) and the source, provide a link to the Creative Commons licence, and indicate if changes were made. The images or other third party material in this article are included in the article's Creative Commons licence, unless indicated otherwise in a credit line to the material. If material is not included in the article's Creative Commons licence and your intended use is not permitted by statutory regulation or exceeds the permitted use, you will need to obtain permission directly from the copyright holder. To view a copy of this licence, visit http://creativecommons.org/licenses/by/4.0/. The Creative Commons Public Domain Dedication waiver (http://creativecommons.org/publicdomain/zero/1.0/) applies to the data made available in this article, unless otherwise stated in a credit line to the data.

[1-3]. Miyashita et al. [4] found no significant correlation between nerve recovery and percentage of spinal canal stenosis and provided evidences questioning the need to remove the retropulsed bone fragments in thoracolumbar fractures combined with nerve injury. Therefore, a new method that can effectively treat thoracolumbar burst fractures without decompression of the spinal canal remains to be found in the future.

Short-segment Schanz screw fixation implanted in an oblique downward direction, which was firstly proposed by us in our previous study [1], is a safe and effective 
method for the treatment of lumbar burst fracture combined with incomplete nerve injury without complications such as screw breakage, screw loosening, and recollapse of the injured vertebra. Short-segment Schanz screw fixation implanted in an oblique downward direction can achieve an upward and forward reduction of the anterior column, middle column, and the posterior column, thus resulted in a better reduction of the downward and backward retrodisplaced vertebra. Therefore, with this method, the available reduction of burst fractured vertebra $(\mathrm{LSC} \geq 7)$ and spinal canal decompression can be achieved without laminectomy even if when the spinal stenosis was severe, and therefore, it is better than the screw insertion parallel to the endplates, which hardly reduced the intraspinal bone fragments without laminectomy $[5,6]$.

Although our new method has been clinically successful, the biomechanical properties of a short-segment Schanz screw implanted in an oblique downward direction have not been reported. In this study, the Universal Spine System (USS) instrumentation reduction model for adjacent vertebrae (T12 and L2) of lumbar 1 vertebra burst fracture (LSC $\geq 7$ ) based on load-sharing classification (LSC) [7] was established for the first time using the finite element method. The model was used to evaluate the screw stress and the displacement of the injured vertebrae when the downward inserted angle between the long axis of the screws and superior endplate of the adjacent $(\mathrm{T} 12 / \mathrm{L} 2)$ vertebrae was set to $0^{\circ}$ (group $\left.\mathrm{A}\right), 5^{\circ}$ (group B), $10^{\circ}$ (group C), and $15^{\circ}$ (group D), during flexion/extension, lateral bending, and rotation. We hope to verify the feasibility and related biomechanical basis of our method of short-segment Schanz screw instrumentation implanted in an oblique downward direction using the finite element method.

\section{Methods}

The study was approved by the Ethics Committee of Zhongshan Hospital affiliated to Dalian University, and written informed consent was obtained from all volunteers. A total of 6 ( 5 males and 1 female) healthy young people participated in the experiment. Patients or the public were not involved in the design, conduct, reporting, or dissemination plans of our research. The average age was $27.50 \pm 2.51$ years old, the height was $175.50 \pm$ $5.92 \mathrm{~cm}$, and the body weight was $76.83 \pm 7.70 \mathrm{~kg}$.

\section{The finite element model}

\section{Normal T12-L2 model}

The DICOM format data of the relevant thoracolumbar images of 6 healthy volunteers were obtained after continuous scanning with $0.75-\mathrm{mm}$ layer thickness using Philips 64-slice spiral computed tomography (CT), followed by Mimics 17.0 (Materialize Inc., Leuven,
Belgium), Geomagic studio 2013 (3D Systems, software such as Raindrop Geomagic Inc. USA), and Hyperwork 14.0 (Altair Engineering, Inc., Executive Park, CA, USA) to create the finite element models. Firstly, the CT data in DICOM format were exported to Mimics to obtain a multi-layer continuous image of the coronal, sagittal, and horizontal positions, and the appropriate gray value was set to 275 to highlight the bone structure. The three vertebrae of the T12-L2 segment were subjected to Thresholding, Region Growing, Edit Masks, and Calculate $3 \mathrm{D}$ to reconstruct the preliminary three-dimensional geometric model. Subsequently, the model was then imported into the Geomagic studio software in STL format. Grid doctor was used to smooth the surface of the model, repair the holes, and remove the spikes. The model was then fitted to an accurate NURBS surface using the probabilistic curvature method at the exact surface stage. Finally, the NURBS surface was imported into the Hypermesh software in Iges format for meshing, and the corresponding structures were established including the vertebral body, intervertebral disc, and paraspinal ligament. The vertebral body is composed of the cortical bone, cancellous bone, and endplate, and the thickness of the cortical bone and endplate is set to 1 $\mathrm{mm}$. The intervertebral disc consisted of the nucleus pulposus (NP) and annulus fibrosus. The volume ratio of the annulus fibrosus to NP was set to $7: 3$. The vertebral body is bound to the adjacent intervertebral disc. The thickness of the cortical bone and endplate was set to $1 \mathrm{~mm}$, the thickness of the articular cartilage is 0.3 $\mathrm{mm}$, and the volume of the annulus fibrosus is 50 to $60 \%$. The model was endowed with materials and properties according to previous studies $[8,9]$, and T3D2 units were used instead of ligaments. The complete normal T12-L2 segment model includes 450,868 $\pm 55,070$ elements and 119,200 $\pm 13,876$ nodes.

\section{Internal fixation model}

The USS Fracture System model fixation was simulated using Siemens NX 10.0 (Siemens PLM Software, Germany). The fracture clamp was simplified, and the thread was ignored. USS fracture fixation was simulated using Geomagic to complete the model assembly and adjustment of the angle of screw placement. The screw placement was performed using a Roy-Camille method. The screw entrance point should be situated at the crossing of 2 lines on a typical bony crest. The horizontal line should pass through the middle of the transverse process; the vertical line is given by the articular process $1 \mathrm{~mm}$ under the facet joint. The internal fixation model is saved as an IGS format file in the same coordinate system as the vertebral model. Mesh was divided by a tetrahedral unit with a side length of $1.5 \mathrm{~mm}$ in HyperMesh. 
After the reduction of thoracolumbar burst fractures, the wedge-shaped bone defect area, which was wide in the front and narrow in the back, was found in the sagittal position (Fig. 1a). The methods reported in our previous studies [10] were used to simulate the LSC-based fracture model, with a vertebral anterior column compression of $65 \%$ and a kyphotic correction angle of $15^{\circ}$ (LSC $\geq 7$ points), through wedge resection of part of the normal vertebral body. The ratio of anterior upper vertebral body height above the bony defect $(\mathrm{AUVH})=$ $\mathrm{AUVH} / \mathrm{AVH}$ (anterior vertebral body height) $\mathrm{x} 100 \%$; the ratio of anterior bony defect height $(\mathrm{ADH})=\mathrm{ADH} /$ $\mathrm{AVH} \times 100 \%$; and the ratio of anterior lower vertebral body height below the bony defect $(\mathrm{ALVH})=\mathrm{ALVH} /$ $\mathrm{AVH} \times 100 \%$. The reduction height of the injured vertebra was set to $100 \%$. After reduction, the ratio of AUVH, the ratio of $\mathrm{ADH}$, and the ratio of $\mathrm{ALVH}$ were $15 \%$, $50 \%$, and $35 \%$, respectively (Fig. $1 \mathrm{~b}$ ).

For the four models, the downward inserted angle between the long axis of the screws and superior endplate of the adjacent vertebrae was set to $0^{\circ}$ (group A), $5^{\circ}$ (group B), $10^{\circ}$ (group C), and $15^{\circ}$ (group D) (Fig. 2). The screws were all inserted below the anterior cortical bone, and the screw insertion depth accounts for more than 97\% of the screw-path length (SPL). The diameters of Schanz pedicle screws and connecting rods are $6.2 \mathrm{~mm}$ and $6 \mathrm{~mm}$, respectively [10]. For the $15^{\circ}$ model, the inserting position of the screw of the upper and lower screws moved upward by $3.14 \pm 1.92 \mathrm{~mm}$ and $3.32 \pm$ $0.96 \mathrm{~mm}$, respectively, than that of the other groups to avoid contacting the lower endplate. Assembly was performed using Geomagic, and the junction of the screw and the bone is a continuous mesh and sharing node in Hyperwork.

\section{Finite element analysis}

We simulated 4 groups according to the downward inserted angle between the long axis of the screws and superior endplate of the adjacent vertebrae, $0^{\circ}$ of group
A (parallel to the endplate) and other three groups all in an oblique downward: respectively $5^{\circ}, 10^{\circ}$, and $15^{\circ}$. There are 6 models in each group.

The concentrated downward pressure along the $Z$-axis direction (vertical load) applied to the upper surface of the T12 vertebral body was used to simulate the gravity of the human body when standing upright. The torque applied is a rotating torque that makes the vertebral body rotate in an axial direction, which was used to simulate the role of the paravertebral muscles in driving the spine to perform various activities including flexion/ extension, lateral bending, and rotation [11-13]:

1) Vertical loads of $350 \mathrm{~N}$.

2) Torque of $7.5 \mathrm{Nm}$ during flexion/extension, lateral bending, and rotation, and a vertical load of $350 \mathrm{~N}$.

\section{Statistical analysis}

Statistical analysis was performed using the SPSS 20.0 software (IBM, USA). Values are presented as mean \pm standard deviation (SD). Data between the different groups during flexion/extension, lateral bending, and rotation were compared by one-way ANOVA. A $P$ value of less than 0.05 was considered statistically significant.

\section{Results}

\section{Validation of the model}

In this study, the range of motion (ROM) of T12/L1 and L1/L2 vertebra of the normal T12-L2 model during flexion/extension, lateral bending, and rotation was similar to those of Yamamoto et al. [14] and Panjabi et al. [15]. Therefore, the T12-L2 model in this study was valid for further analyses.

\section{Pedicle screw stress}

The maximum stress occurred at the interface of the proximal pedicle and cortical bone, and the stress of the upper screw is greater than that of the lower screw (Figs. 3 and 4). The maximum stress of the screws had
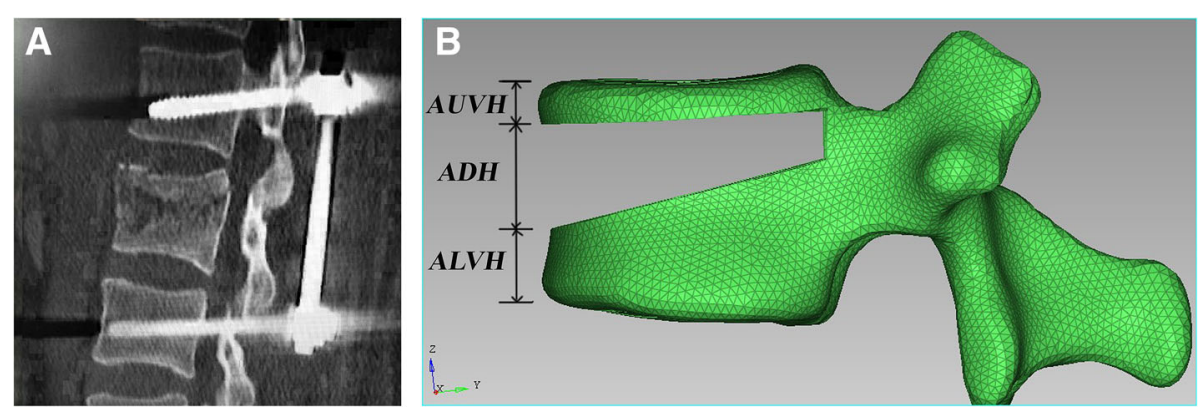

Fig. 1 a After the reduction of thoracolumbar burst fractures, the wedge-shaped bone defect area in the sagittal position was wide in the front and narrow in the back. $\mathbf{b}$ AUVH accounts for $15 \%$ of the leading edge of the vertebral body, ADH accounts for $50 \%$ of the leading edge of the vertebral body, and ALVH accounts for $35 \%$ of the leading edge of the vertebral body. AUVH, anterior upper vertebral body height above the bony defect; $\mathrm{ADH}$, anterior bony defect height; $\mathrm{ALVH}$, anterior lower vertebral body height below the bony defect 

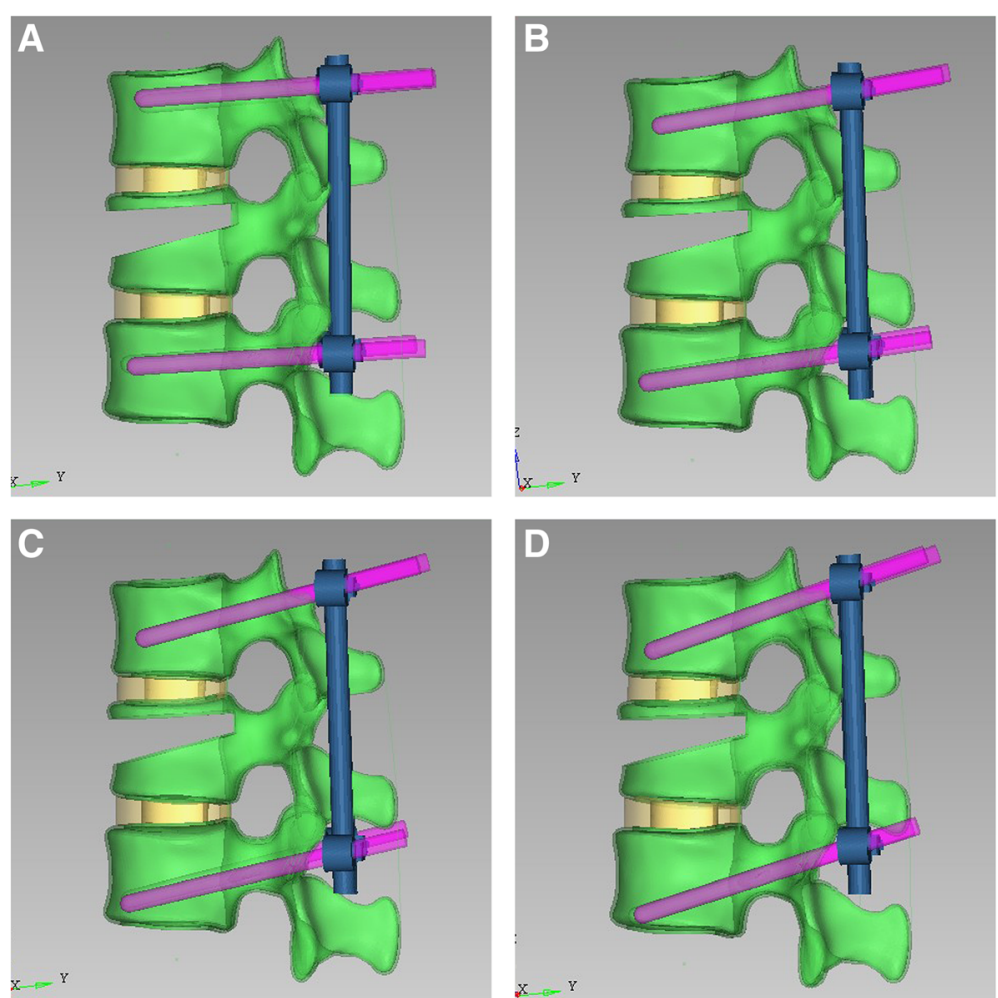

Fig. 2 Schanz pedicle screw fixation models when the downward inserted angle between the long axis of the screws and superior endplate of the adjacent vertebrae was set to $\mathbf{a} 0^{\circ}, \mathbf{b} 5^{\circ}, \mathbf{c} 10^{\circ}$, and $\mathbf{d} 15^{\circ}$

no statistical difference among the four groups $(P>0.05$, Fig. 5).

\section{Postoperative axial displacement/micro-motion of the lumbar 1}

The displacement of the injured vertebra was more in the leading edge and less in the trailing edge. There was a "cohesive" displacement/micro-motion between the upper vertebral body and the lower vertebral body of lumbar 1 due to the downward displacement/micro-motion of the upper vertebral body and the upward displacement/micro-motion of the lower vertebral body (Figs. 6 and 7). The axial displacement of the injured vertebrae increased with the increase of the angle during flexion/extension, lateral bending, and rotation, but there was no statistical difference among the four groups $(P>0.05$, Fig. 8).

\section{Discussion}

Previous finite element simulation of the fracture models is not widely accepted and is different from clinical practice due to the removal of the part of the cortical or cancellous bone, which is not suitable for comparative analysis of various finite element studies [11, 16, 17]. LSC is a widely accepted vertebral body load scoring standard for the treatment of thoracolumbar fractures.
The LSC system is a straightforward, quantitative method of describing the following 3 aspects: (1) extent of bony comminution, (2) amount of fracture displacement, and (3) extent of kyphosis in a vertebra fracture, which can well meet the requirements of finite element for quantitative simulation of type A fractures. Each aspect was recorded as 1 point (mild), 2 points (moderate), and 3 points (severe) according to the fracture severity. The most severe fracture was calculated as a maximum of 9 points. In 2018, De Iure et al. [18] retrospectively analyzed 121 cases of unstable thoracolumbar fractures and concluded that the LSC-based injured vertebral assessment can predict the risk of posterior fixation failure. Based on LSC, our previous finite element analysis compared short-segment instrumentation with conventional pedicle screws and the Schanz pedicle screw in lumbar 1 fractures, indicating that Schanz pedicle screws were recommended for unstable fractures because the screws have a lower risk of screw breakage compared with conventional pedicle screws [10].

In order to better evaluate the maximum stress of screws and the displacement of the injured vertebra defect area when short-segment Schanz screws were implanted in an oblique downward direction with different angles, the following settings were made using the LSCbased injured vertebra model. Healthy young people 

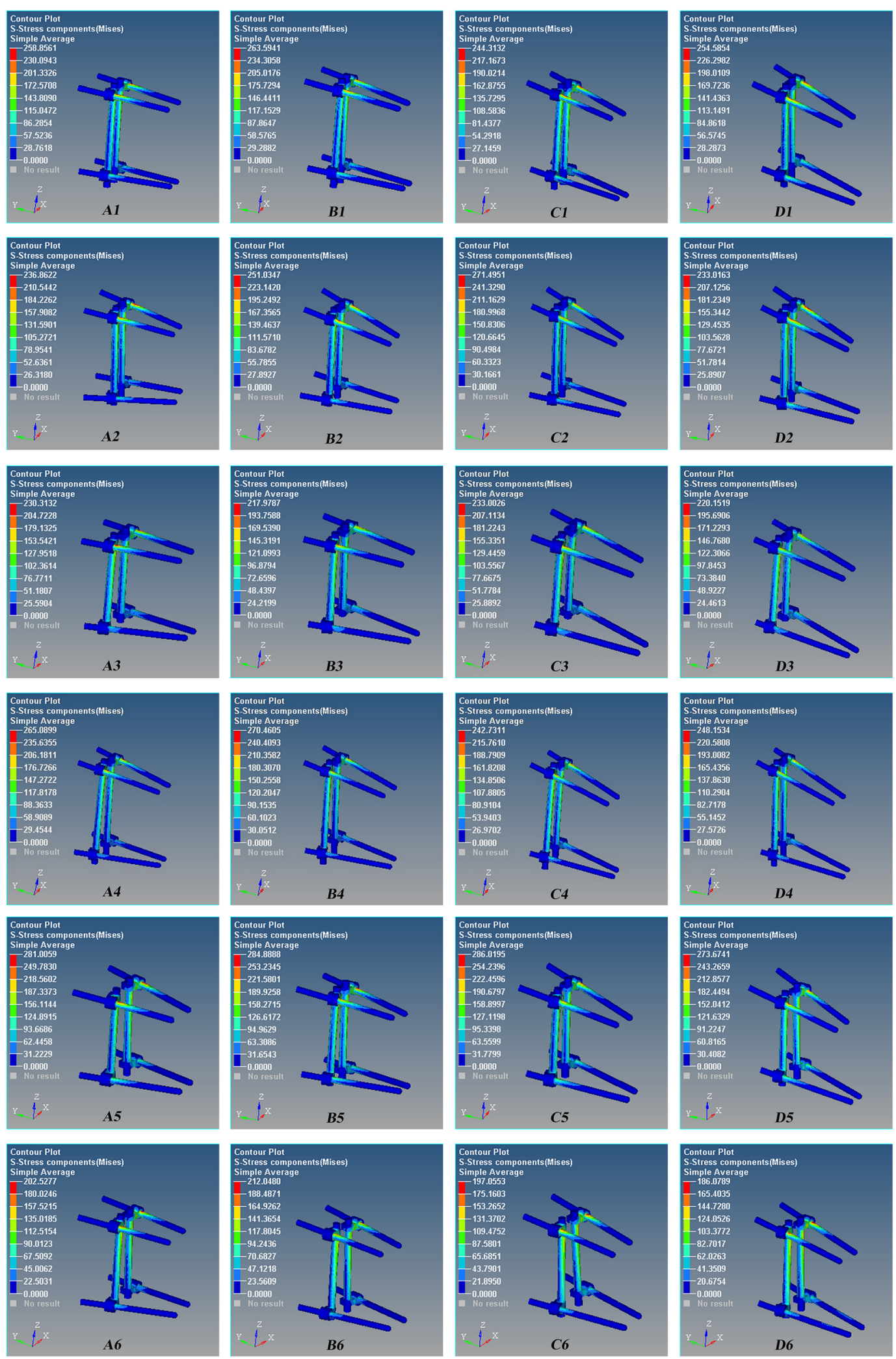

Fig. 3 The stress nephogram of the Schanz pedicle screw for the $L 1$ severe fractures after $T 12$ and $L 2$ pedicle screw fixation during anterior flexion. Red is the maximum stress. The maximum stress occurred at the interface of the proximal pedicle and cortical bone, and the stress of the upper screw is greater than that of the lower screw. A1-A6 $0^{\circ}, \mathbf{B 1}-\mathbf{B 6} 5^{\circ}, \mathbf{C 1}-\mathbf{C 6} 10^{\circ}$, and $\mathbf{D 1 - D 6} 15^{\circ}$. There are 6 models in each group 

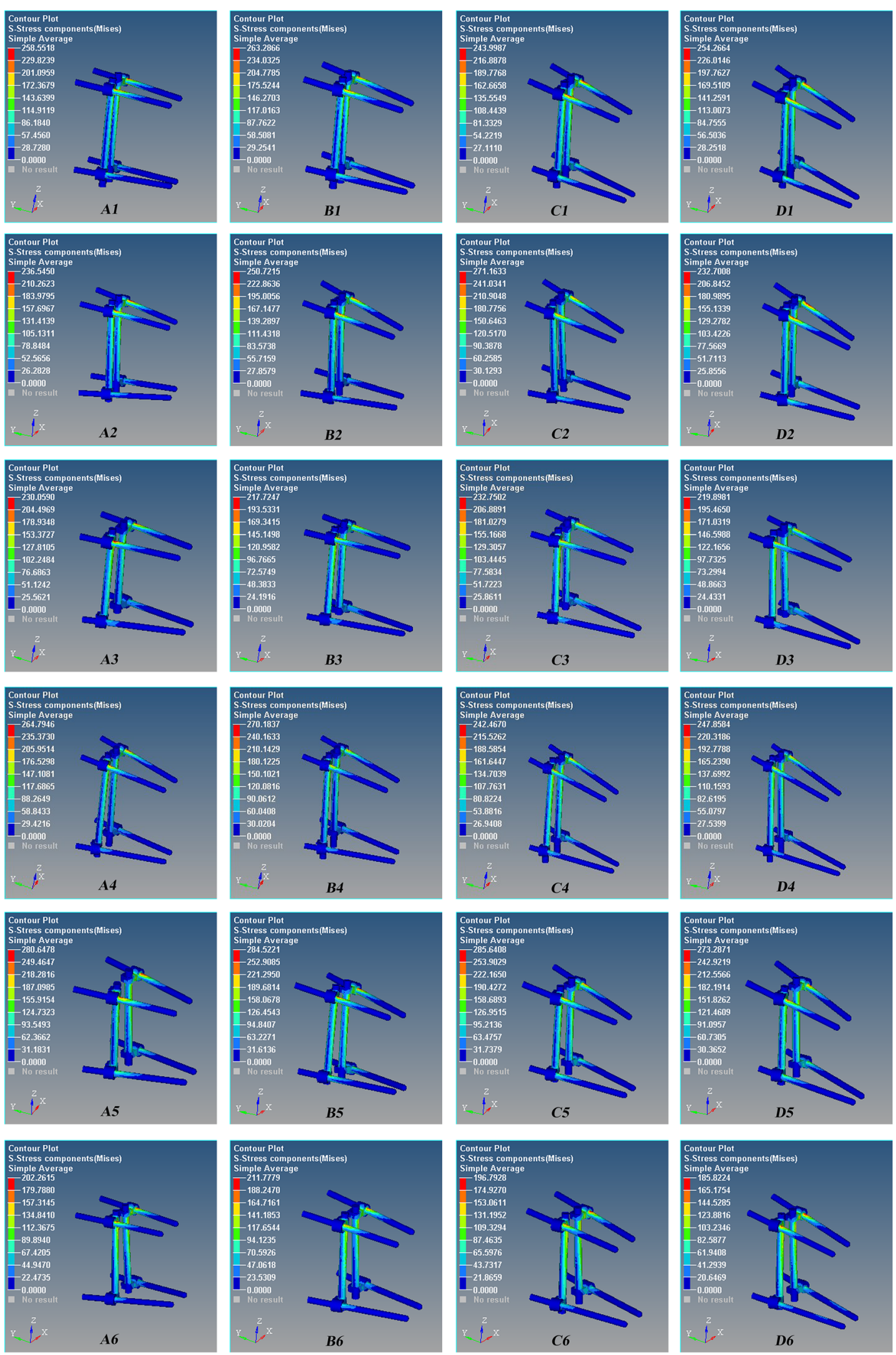

Fig. 4 The stress nephogram of the Schanz pedicle screw for the L1 severe fractures after T12 and L2 pedicle screw fixation during posterior extension. Red is the maximum stress. The maximum stress occurred at the interface of the proximal pedicle and cortical bone, and the stress of the upper screw is greater than that of the lower screw. A1-A6 $0^{\circ}, \mathbf{B} \mathbf{1}-\mathbf{B} \mathbf{6} 5^{\circ}, \mathbf{C} \mathbf{1}-\mathbf{C 6} 10^{\circ}$, and $\mathbf{D 1} \mathbf{1} \mathbf{D 6} 15^{\circ}$. There are 6 models in each group 


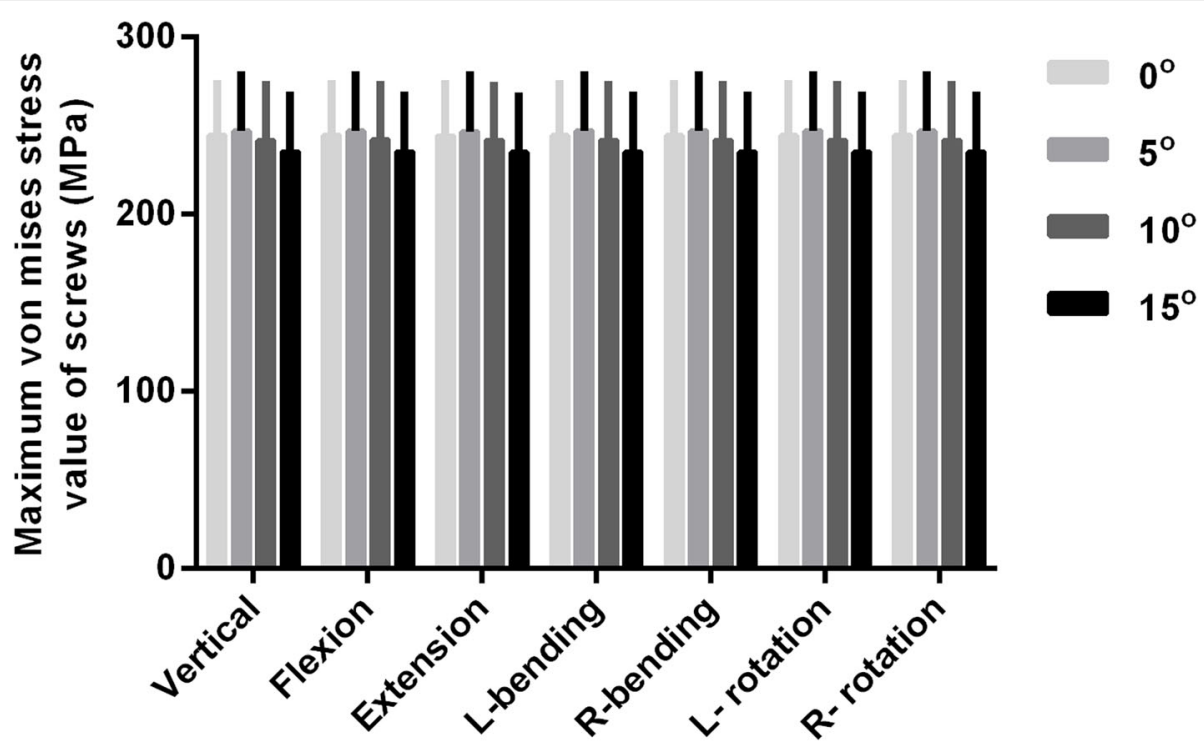

Fig. 5 Comparison of the maximum stress of the screws when the downward inserted angle between the long axis of the screws and superior endplate of the adjacent vertebrae was set to $0^{\circ}$ (group A), $5^{\circ}$ (group B), $10^{\circ}$ (group C), and $15^{\circ}$ (group D) during flexion/extension, lateral bending, and rotation. The maximum stress of the screws has no statistical difference among the four groups $(P>0.05)$

have less degeneration and proliferation of thoracolumbar spine and intervertebral disc, and the spine is easier to simulate and the model is closer to reality compared with the degenerated spine (vertebral osteophytes, elastic changes of ligaments, degeneration of intervertebral discs, etc.). Therefore, our study is based on six healthy young people. The height restoration compression of the vertebral body was set to be $100 \%$. The anterior edge compression of the vertebra was $65 \%$ (3 points), the kyphotic correction angle was $15^{\circ}$ ( 2 points), and the fracture extent and the displacement of broken bone were 1-3 points; therefore, the total LSC was 7-9 points. Similar to our previous study [10, 19], the bone defect area was a triangular-like bony defect which was wide in the front and narrow in the back. In addition, the upper vertebral body of the bony defect retains $15 \%$ of the bone for analysis.

Using the above model, four groups were set in our study according to the downward inserted angle between the long axis of the screws and superior endplate of the adjacent vertebrae: $0^{\circ}$ of group $\mathrm{A}, 5^{\circ}$ of group $\mathrm{B}, 10^{\circ}$ of group $\mathrm{C}$, and $15^{\circ}$ of group $\mathrm{D}$. The results of the comparative analysis showed that there was no significant difference in the maximum stress among the groups during flexion/extension, lateral bending, and rotation with the increase of the angle $(P=0.92)$. The maximum stress of each group was lower than $250 \mathrm{MPa}$, which is far below the fatigue threshold of $550 \mathrm{MPa}$ [20], indicating a lower risk of screw breakage in all groups during all these situations. And this is consistent with our previous clinical results which showed that Schanz screw downward fixation is safe and effective in the treatment of lumbar burst fracture [1].

The effect of short-segment pedicle screw fixation for thoracolumbar spine fractures is load-bearing and transvertebral stress conduction. In our previous study [1], we proposed that the conventional pedicle screw has a similar load-bearing capacity to the Schanz screw; however, the latter has a better conduction capacity because the structure of the Schanz screw rod (similar to "]["-shaped conduction) is more similar to the lumbar posterior column (butterfly-shaped conduction) than conventional pedicle screw (similar to "| |"-shaped conduction). In addition, we first proposed that the difference in conduction ability is the key to the screw breakage and that is why the Schanz screw fixation can effectively treat severe burst fractures of the thoracolumbar segment than conventional screw fixation. Therefore, the nonsignificant differences in the maximum stress among the groups in the present study suggest that the stress conduction does not change significantly with the change of the oblique angle. Similar to other studies [13, $16,21]$, the maximum stress of screws in each group in this study was located in the upper screws during anterior flexion, which was mainly because the stress during anterior flexion was conducted from the upper pedicle screw to the lower pedicle screw across the injured vertebra and adjacent intervertebral disc.

Despite no screw breakage occurred in Schanz pedicle screw fixation for the treatment of severe fracture $[1,2]$, it still has the disadvantages of postoperative re-collapse of the injured vertebra [22]. Jang et al. retrospectively 

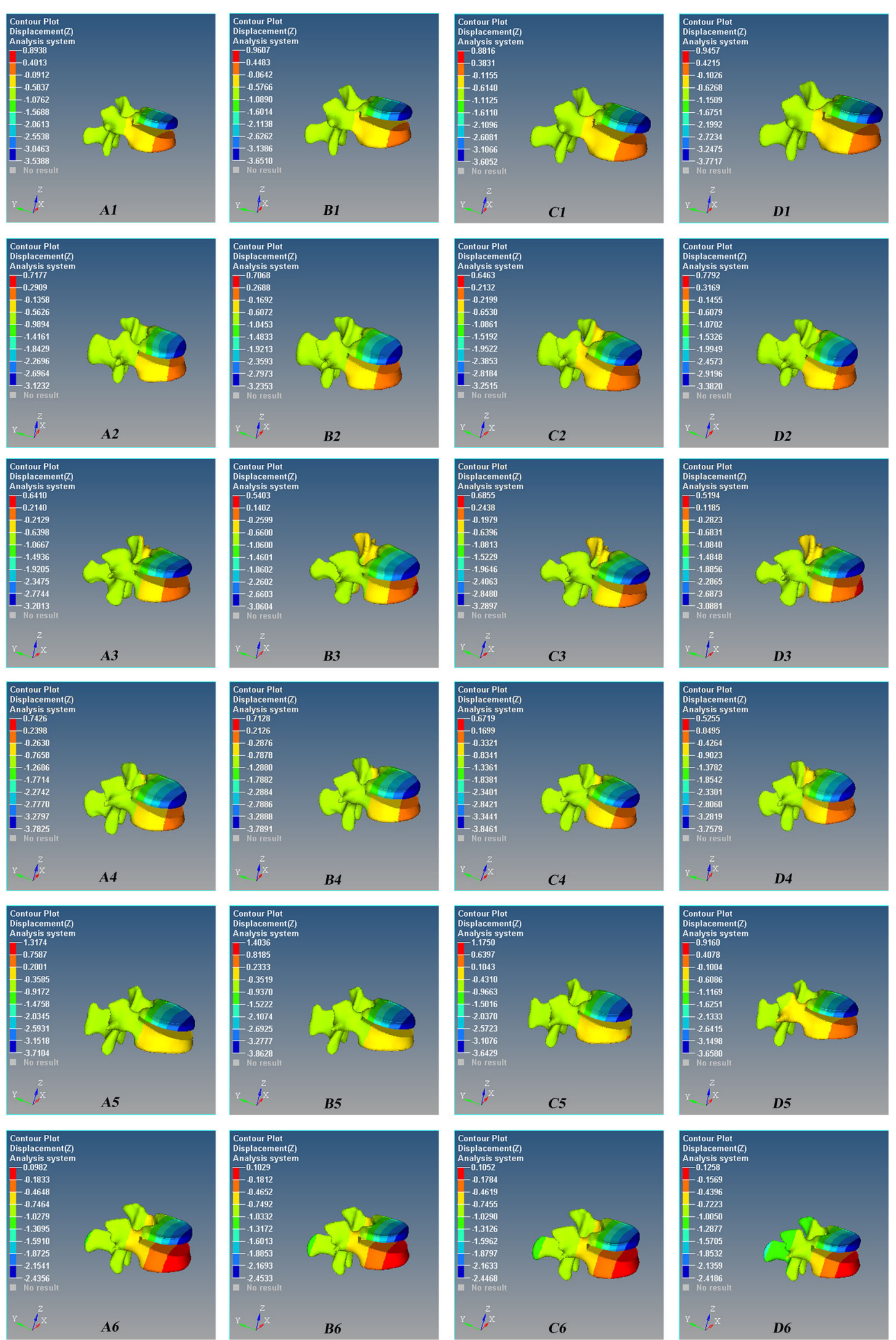

Fig. 6 Axial (Z-axis) displacement nephogram of the micro-motion of the vertebral defect area of Schanz pedicle screw for L1 severe fracture during anterior flexion. Red is the maximum displacement upward, and blue is the maximum displacement downward. A1-A6 $0^{\circ}, \mathbf{B 1}-\mathbf{B 6} 5^{\circ}, \mathbf{C 1}-\mathbf{C 6} 10^{\circ}$, and D1-D6 $15^{\circ}$. There are 6 models in each group 

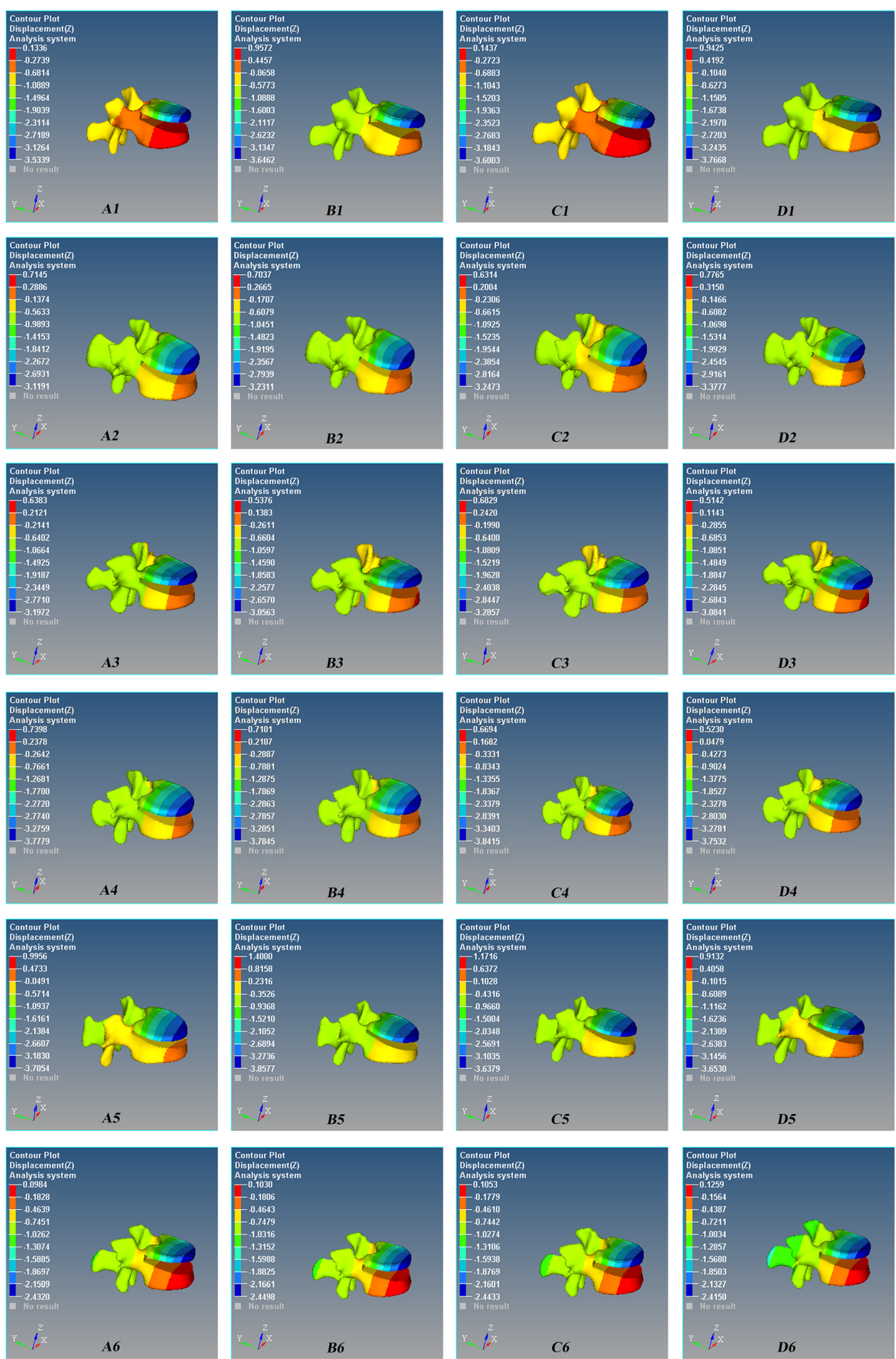

Fig. 7 Axial (Z-axis) displacement nephogram of the micro-motion of vertebral defect area of Schanz pedicle screw for L1 severe fracture during posterior extension. Red is the maximum displacement upward, and blue is the maximum displacement downward. A1-A6 $0^{\circ}, \mathbf{B 1}-\mathbf{B 6} 5^{\circ}$, C1- C6 $10^{\circ}$, and D1-D6 $15^{\circ}$. There are 6 models in each group 


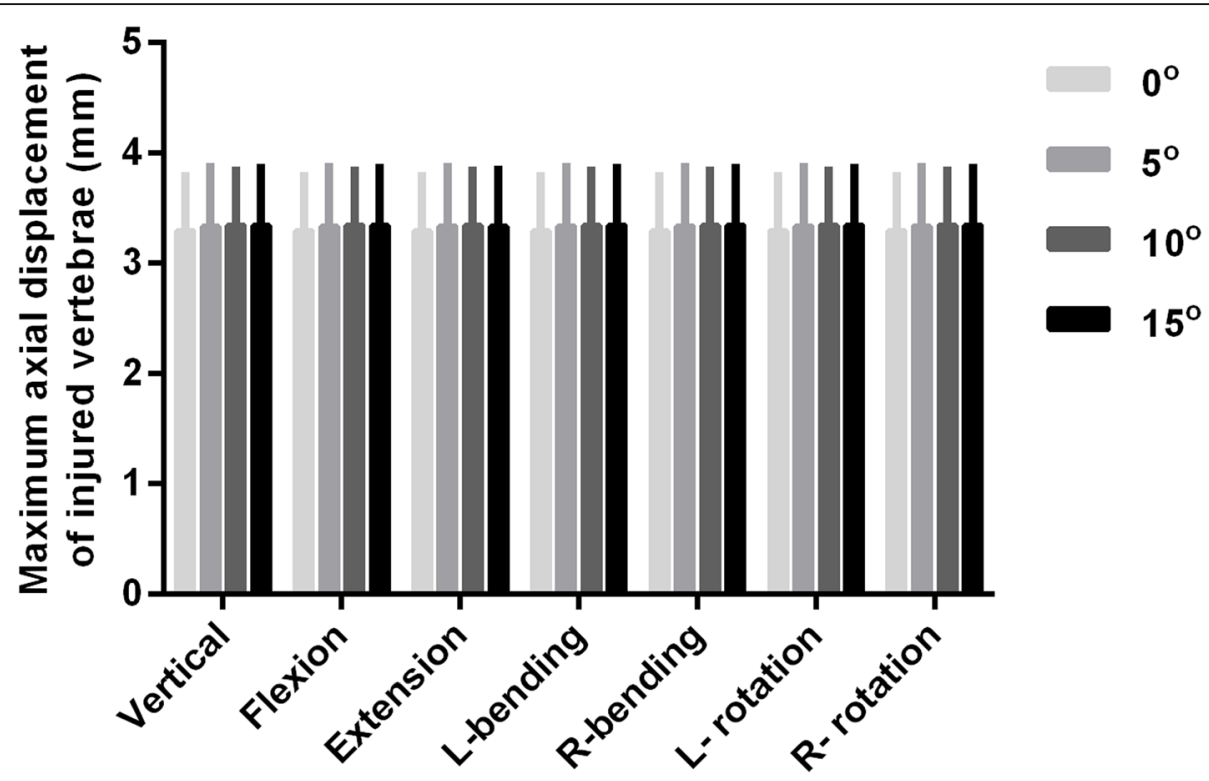

Fig. 8 Comparison of the maximum axial (Z-axis) displacement of the vertebral defect area when the downward inserted angle between the long axis of the screws and superior endplate of the adjacent vertebrae was set to $0^{\circ}$ (group A), $5^{\circ}$ (group B), $10^{\circ}$ (group C), and $15^{\circ}$ (group D) during flexion/extension, lateral bending, and rotation. The axial displacement of the injured vertebrae increased with the increase of the angle during flexion/extension, lateral bending, and rotation, but there was no statistical difference among the four groups $(P>0.05)$

analyzed 208 cases of thoracolumbar burst fracture using conventional open pedicle screw fixation and found that age at operation ( $>43$ years old) and preoperative body height loss $(>54 \%)$ were independent predictors of recollapse [23]. In our previous studies, we found that the compression displacement/micro-motion of the bony defect of injured vertebrae during flexion may contribute to postoperative re-collapse of the injured vertebrae, and the "cohesive" displacement/micro-motion of the bony defect of unstable fractures was larger than that of moderate fractures under the same screws [10]. However, to the best of our knowledge, there were few finite element studies simulating and evaluating the bone defect of the injured vertebra after reduction [11, 17, 24].

In this present study, there was also a "cohesive" displacement/micro-motion of the bone defect area; however, the change of the oblique angle did not change the displacement/micro-motion of the bone defect area. By the combined use of Schanz pedicle screw and thoracolumbo-sacral orthosis (TLSO) brace in our previous study [1] and the study of Aono et al. [2], we not only ensured the clinical efficacy but also prevented the recollapse of the injured vertebra. We speculated that TLSO brace could limit the thoracolumbar sacral movement to reduce the injured vertebra displacement and thus avoid the re-collapse of the injured vertebrae [1]; however, further biomechanical and clinical studies are needed to confirm this statement.

Short-segment Schanz screw implanted in an oblique downward direction with different angles did not change the maximum stress of screws and the displacement of the injured vertebra defect area, the following deficiencies need to be further verified: (1) There were 6 samples in each group in our study, and more samples are needed to confirm this finding, and studies on the stress of the pedicle screw based on middle-aged and older people remain to be further studied. (2) Whether the biomechanical results of related cadaver models are consistent. (3) The anti-collapse effect of the TLSO brace needs further exploration.

\section{Conclusion}

In conclusion, short-segment Schanz screw implanted in an oblique downward direction with different angles did not significantly change the maximum stress of screws and the displacement of the injured vertebra defect area. This is a safe method to treat severe L1 burst fracture.

\section{Abbreviations}

USS: Universal Spine System; CT: Computed tomography; NP: Nucleus pulposus; AUVH: Anterior upper vertebral body height above the bony defect; AVH: Anterior vertebral body height; ADH: Anterior bony defect height; ALVH: Anterior lower vertebral body height below the bony defect; ROM: Range of motion; TLSO: Thoraco-lumbo-sacral orthosis

\section{Acknowledgements \\ None.}

\section{Authors' contributions}

SY and $J L$ conceived and designed the study. JL and SY collected and assembled the data. $J L, S Y, F Z$, and $J L$ analyzed and interpreted the data. CX, $H W$, and CC performed the literature search. JL performed the writing of the manuscript. The authors read and approved the final manuscript. 


\section{Funding}

This work was supported by the National Natural Science Foundation of China (grant 30870647) and the Dalian Medical Scientific Research Project (grant 1811110)

\section{Ethics approval and consent to participate}

This study was approved by the Ethics Committee of Affiliated Zhongshan Hospital of Dalian University.

\section{Consent for publication}

Signed informed consent was obtained from each patient.

\section{Competing interests}

The authors indicated no potential conflicts of interest.

Received: 15 June 2020 Accepted: 14 October 2020

Published online: 17 November 2020

\section{References}

1. Yang S, Shang DP, Lu JM, Liu JF, Fu DP, Zhou F, Cong Y, Lv ZZ. Modified posterior short-segment pedicle screw instrumentation for lumbar burst fractures with incomplete neurological deficit. World Neurosurg. 2018;119: e977-e85

2. Aono $\mathrm{H}$, Ishii $\mathrm{K}$, Tobimatsu $\mathrm{H}$, Nagamoto $\mathrm{Y}$, Takenaka S, Furuya M, Chiaki H, Iwasaki M. Temporary short-segment pedicle screw fixation for thoracolumbar burst fractures: comparative study with or without vertebroplasty. Spine J. 2017;17:1113-9.

3. Lindtner RA, Mueller M, Schmid R, Spicher A, Zegg M, Kammerlander C, Krappinger D. Monosegmental anterior column reconstruction using an expandable vertebral body replacement device in combined posterioranterior stabilization of thoracolumbar burst fractures. Arch Orthop Trauma Surg. 2018;138:939-51.

4. Miyashita T, Ataka H, Tanno T. Clinical results of posterior stabilization without decompression for thoracolumbar burst fractures: is decompression necessary? Neurosurg Rev. 2012;35:447-54 discussion 54-5.

5. Chen ZD, Wu J, Yao XT, Cai TY, Zeng WR, Lin B. Comparison of Wiltse's paraspinal approach and open book laminectomy for thoracolumbar burst fractures with greenstick lamina fractures: a randomized controlled trial. J Orthop Surg Res. 2018;13:43.

6. Wang K, Zhang ZJ, Wang JL, Huang CA, Huang QS, Chen J, Wu YS, Lin Y, Wang $X Y$, Chen JX, Sheng SR. Risk factor of failed reduction of posterior ligamentatoxis reduction instrumentation in managing thoracolumbar burst fractures: a retrospective study. World Neurosurg. 2018;119:e475-e81.

7. McCormack T, Karaikovic E, Gaines RW. The load sharing classification of spine fractures. Spine (Phila Pa 1976). 1994;19:1741-4

8. Goel VK, Kim YE, Lim TH, Weinstein JN. An analytical investigation of the mechanics of spinal instrumentation. Spine (Phila Pa 1976). 1988;13:1003-11.

9. Spilker RL. Mechanical behavior of a simple model of an intervertebral disk under compressive loading. J Biomech. 1980;13:895-901.

10. Zhou F, Yang S, Liu J, Lu J, Shang D, Chen C, Wang H, Ma J. Finite element analysis comparing short-segment instrumentation with conventional pedicle screws and the Schanz pedicle screw in lumbar 1 fractures. Neurosurg Rev. 2020;43:301-12.

11. Liao JC, Chen WP, Wang H. Treatment of thoracolumbar burst fractures by short-segment pedicle screw fixation using a combination of two additional pedicle screws and vertebroplasty at the level of the fracture: a finite element analysis. BMC Musculoskelet Disord. 2017;18:262.

12. Rohlmann A, Zander T, Rao M, Bergmann G. Realistic loading conditions for upper body bending. J Biomech. 2009:42:884-90.

13. Kubosch D, Kubosch EJ, Gueorguiev B, Zderic I, Windolf M, Izadpanah K, Sudkamp NP, Strohm PC. Biomechanical investigation of a minimally invasive posterior spine stabilization system in comparison to the universal spinal system (USS). BMC Musculoskelet Disord. 2016;17:134.

14. Yamamoto I, Panjabi MM, Crisco T, Oxland T. Three-dimensional movements of the whole lumbar spine and lumbosacral joint. Spine (Phila Pa 1976). 1989:14:1256-60.

15. Panjabi MM, Oxland TR, Lin RM, McGowen TW. Thoracolumbar burst fracture. A biomechanical investigation of its multidirectional flexibility. Spine (Phila Pa 1976). 1994;19:578-85.

16. Li C, Zhou Y, Wang H, Liu J, Xiang L. Treatment of unstable thoracolumbar fractures through short segment pedicle screw fixation techniques using pedicle fixation at the level of the fracture: a finite element analysis. PLoS One. 2014:9:e99156.

17. Xu G, Fu X, Du C, Ma J, Li Z, Tian P, Zhang T, Ma X. Biomechanical comparison of mono-segment transpedicular fixation with short-segment fixation for treatment of thoracolumbar fractures: a finite element analysis. Proc Inst Mech Eng H. 2014;228:1005-13.

18. De lure F, Lofrese G, De Bonis P, Cultrera F, Cappuccio M, Battisti S. Vertebral body spread in thoracolumbar burst fractures can predict posterior construct failure. Spine J. 2018;18:1005-13.

19. Liu J, Yang S, Lu J, Fu D, Liu X, Shang D. Biomechanical effects of USS fixation with different screw insertion depths on the vertebrae stiffness and screw stress for the treatment of the L1 fracture. J Back Musculoskelet Rehabil. 2018;31:285-97.

20. Brown S. Synthetic biomaterials for spinal applications. Burlington: Academic Press; 2006.

21. Wang H, Mo Z, Han J, Liu J, Li C, Zhou Y, Xiang L, Yang L. Extent and location of fixation affects the biomechanical stability of short- or longsegment pedicle screw technique with screwing of fractured vertebra for the treatment of thoracolumbar burst fractures: an observational study using finite element analysis. Medicine (Baltimore). 2018;97:e11244.

22. Lakshmanan P, Jones A, Mehta J, Ahuja S, Davies PR, Howes JP. Recurrence of kyphosis and its functional implications after surgical stabilization of dorsolumbar unstable burst fractures. Spine J. 2009;9:1003-9.

23. Jang HD, Bang C, Lee JC, Soh JW, Choi SW, Cho HK, Shin BJ. Risk factor analysis for predicting vertebral body re-collapse after posterior instrumented fusion in thoracolumbar burst fracture. Spine J. 2018:18: 285-93.

24. Zhao WT, Qin DP, Zhang XG, Wang ZP, Tong Z. Biomechanical effects of different vertebral heights after augmentation of osteoporotic vertebral compression fracture: a three-dimensional finite element analysis. J Orthop Surg Res. 2018;13:32

\section{Publisher's Note}

Springer Nature remains neutral with regard to jurisdictional claims in published maps and institutional affiliations.
Ready to submit your research? Choose BMC and benefit from:

- fast, convenient online submission

- thorough peer review by experienced researchers in your field

- rapid publication on acceptance

- support for research data, including large and complex data types

- gold Open Access which fosters wider collaboration and increased citations

- maximum visibility for your research: over $100 \mathrm{M}$ website views per year

At $\mathrm{BMC}$, research is always in progress.

Learn more biomedcentral.com/submissions 